\section{Hydrogen bond}

The Hydrogen Bond: Recent Developments in Theory and Experiments. Vol. 1: Theory. Pp. viiit 1-390. Vol. 2: Structure and Spectroscopy. Pp. viii +391-888. Vol. 3: Dynamics, Thermodynamics and Special Systems. Pp. viii $+889-1,549$. Edited by P. Schuster, G. Zundel, C. Sandorfy. (North Holland: Amsterdam, New York and Oxford, 1976.) Dfl. 450; $\$ 173.75$.

IT has been a privilege and pleasure to review this treatise. The hydrogen bond is ubiquitous, and the growth in its studies phenomenal. When I recall my student days at Leicester, where Louis Hunter and his group made major contributions using classical methods to the study of the hydrogen bond-and at that time it was thought that this type of interaction occurred only with fluorine, oxygen, and nitrogen-we can realise the enormous strides which have been made in the experimental and theoretical approaches to this phenomenon. Matrix isolation techniques, neutron scattering, magnetic resonance spectroscopies, to name just a few, have added enormous depth and breadth to the subject.

We cannot readily avoid coming across hydrogen bonds in our work; whether we invoke them in proton abstraction mechanisms, or demonstrate them in structural studies. Only very recently it helped to rationalise an apparent anomaly we had observed: a precursor postulated in a room temperature reaction required, after isolation as a crystalline solid, an increase of $100^{\circ} \mathrm{C}$ in temperature to give the same product. A crystal structure determination provided the answer (Cameron et al., Z. Naturforsch., 31b, 1421, 1976): it showed the presence of a 12-membered ring hydrogen-bonded dimer, with some of the shortest recorded $\mathrm{O}-\mathrm{H} \ldots \mathrm{N}$, and $\mathrm{N}-\mathrm{H}$. . . S bonds.

These three volumes (detailed in the title) increase progressively in length and cover most aspects of the subject. Deliberately excluded are the mainly biological investigations, and also largely those devoted to the excited state and relaxation kinetics.

I personally found the studies of hydrogen-bonded systems by X-ray and neutron diffraction studies particularly fascinating. The two methods are critically compared, neutron scattering giving the longer $\mathrm{X}-\mathrm{H}$ bond lengths. This technique also reveals that most hydrogen bonds are not strictly linear, and that in bifurcated hydrogen bonds, the bifurcation is usually uneven.

The topology of the hydrated proton $\mathrm{H}^{+}\left(\mathrm{H}_{2} \mathrm{O}\right)_{n}(n=1,2,3,4,5$, and 6$)$ is discussed. In most cases, at least two different structures could be considered for a given value of $n$.

Examples of symmetric $\mathrm{H}_{5} \mathrm{O}_{2}{ }^{+}$ions (for example, yttrium hydrogen oxalate trihydrate) and asymmetric $\mathrm{H}_{5} \mathrm{O}_{2}{ }^{+}$ions (for example, picrylsulphonic acid tetrahydrate) have been observed by diffraction methods. Similar studies by spectroscopic techniques show the important advances made in this field, and suggest that the symmetric diaquahydrogen ion $\left(\mathrm{H}_{2} \mathrm{O} . \mathrm{H} . \mathrm{OH}_{2}\right)^{+}$is rather more prevalent than the asymmetric monoaquaoxonium ion $\left(\mathrm{H}_{3} \mathrm{O}^{+} . \mathrm{OH}_{2}\right)$.

Major advances in hydrogen-bonded systems have been made using nuclear magnetic resonance spectroscopy and the use of this technique is beautifully demonstrated for the liquid and the solid state.

Perhaps the last two chapters of this treatise, devoted to liquid water and ice respectively, demonstrate most vividly the diversity and complexity to which hydrogen bonding can give rise.

Although the distinguished contributors number almost forty and come from different nationalities, these volumes are written in excellent English, and overlap between chapters is

\section{Immunological recipes}

Techniques in Clinical Immunology. Edited by R. A. Thompson. Pp. 241. (Blackwell Scientific: Oxford, 1977.) Paperback $£ 6.25$.

BLACKWELL Scientific Publications have over the years accumulated a long list of 'titles' in immunology. The standard they and their authors have maintained is generally high. The books range from accounts of the proceedings of specialist conferences to the practical handbook under consideration here. This latter has eleven chapters on techniques commonly used in clinical immunology. It is parochial in that the kind of immunology under consideration is that practised in British hospitals and research institutes-it makes little or no attempt to be international.

Each chapter is written by a person who is involved on a day to day basis with the methods described. Every chapter starts with a short theoretical introduction to the topic before launching onto the collection of recipes which forms the bulk of the text. I am stuck, without doing the cooking myself, in trying to decide whether the minimal. The editors must be congratulated. Most chapters cover the literature up to the period 1973-74, some with appendices and notes added in proof up to 1975 , a very creditable achievement in an edited treatise. The volumes are beautifully produced and printing errors are scarce. It is a pity that blurring of pp 1,337-1,352, at least in my copy, slightly mars the overall impression. All volumes contain a subject index (covering all three). Volume 3 has also an author index.

Experimentalists (like myself) however, may well find volume 1 heavy going. It is a pity that individual volumes do not seem to be available.

I have so far only considered the quality of this treatise. Alas, we must also pay attention to its cost. A price of more than $£ 100$ will deter individual buyers and many libraries in this country. A crying shame as these volumes with their wide, almost universal, appeal ought to be on all library shelves.

I was instructed and stimulated by reading these volumes; I am saddened by the thought, that not enough scientists may be able to share this experience.

Robert A. Shaw

Robert A. Shaw is Professor of Chemistry at Birkbeck College, University of London, $U K$.

reclpes work. They look alright.

The emphasis is toward the classical formulations of immunology rather than the new cell-mediated brand. There is, for example, no chapter on skin-testing. Little is said throughout the book of the indications for any particular test and only rarely about interpretation of results. Perhaps the most thoughtful chapter is that by Irene Batty on quality control. Few of the previous chapters on such disparate matters as the quantification of immune complexes, agglutination of cells or neutrophil leukocyte function tests (an intriguing choice this for an immunology text), give an indication of the way of handling the information gained. Dr Batty lays out in a clear way the basic necessity of quality control charts and describes the area of activity for which standardisation procedures are possible. Relatively few of the other chapters fall into this category.

It is a useful book carefully compiled which is too expensive for a paperback that might sell well.

A. J. S. Davies

A. J. S. Davies is Professor of Immunobiology in the University of London, working at the Chester Beatty Research Institute, London, UK, 